\title{
Entre renglones rosas y azules, dos perspectivas de la mujer moderna. Una aproximación a las representaciones femeninas de 1919, en las revistas quiteñas Flora y Caricatura.
}

\section{Between pink and blue lines, two perspectives about the modern woman. An aproximation toward the femenin representatios in 1919 from Quitonian magazines Flora and Caricatura}

\section{Mayte Peñaherrera}

Historiadora del Arte, Pontifica Universidad Católica del Ecuador vivi_mayte.p@hotmail.com

Fecha de recepción: 19 de julio de 2019

Fecha de aprobación: 21 de diciembre de 2019

\begin{abstract}
Resumen
Este trabajo ofrece una comparación de imágenes femeninas vistas en dos publicaciones: una editada por mujeres y otra por hombres. De ahí el nombre del presente artículo; puesto que se verán las diferencias entre las líneas e ilustraciones desde las perspectivas de las revistas quiteñas modernistas Caricatura y Flora de 1919. Además de ello, se buscará entender las mencionadas representaciones femeninas enmarcadas dentro de una sociedad en los albores de la década de los años veinte.
\end{abstract}

Palabras clave: Modernismo, Caricatura, Flora, imágenes femeninas.

\begin{abstract}
This paper offers a comparison between feminine images through two publications: the first one edited by women, while the second one, by men. From there, it was the article's name, because it shows the differences between the lines and the illustrations of modern Quitonian magazines: Caricatura and Flora. This paper also tries to understand the mentioned feminine representations in a society at the beginning of the twenties.
\end{abstract}

Keywords: Modernism, Caricature, Flora, Feminine images. 


\section{Introducción}

Las concepciones que sobre la mujer se tenían en 1919 en la capital ecuatoriana no eran homogéneas, pues existían en ellas muchos matices. Lo que pretendemos en este trabajo es mostrar las diferencias entre imágenes femeninas, concebidas por mujeres, y contrastarlas con aquellas concebidas por hombres, viendo así, la heterogeneidad de las mismas. La selección de las publicaciones (Caricatura y Flora) para el presente análisis no se realizó al azar, esta respondió a varios factores que mencionaremos a continuación. Si bien es cierto que en los albores de 1920 circularon otras revistas, también es verídico que en la actualidad, nuestros archivos históricos no cuentan con todos los ejemplares de las mismas. Por el contrario, Caricatura y Flora, son más accesibles para la consulta dado que se cuenta con casi todos sus números impresos. Además de ello, se tomó en consideración que ambas revistas pretendían llegar a un grupo social común: la élite ecuatoriana. Finalmente, diremos que hemos escogido las fuentes a trabajar, debido a que el tiraje de ambas coincidió con un año clave, 1919, donde creemos que se marcó el fin de un siglo y el comienzo de otro.

Con este trabajo pretendemos determinar si para 1919 las imágenes de la mujer, tanto a nivel visual como textual, manifiestan remanentes del siglo XIX o si bien, estas adquieren matices nuevos y se presentan totalmente distintas. Para tal propósito, dentro de este artículo, se incluirá un breve recuento de la imagen femenina manejada antes de 1919. Posteriormente, se verá la comparación mencionada vista en los artículos de las revistas y finalmente, se realizará una revisión de las ilustraciones y fotografías incluidas en las mismas.

\section{Contexto histórico}

Aún con rezagos del siglo pasado los primeros años del siglo XX, a nivel mundial, se inauguraron no tan favorablemente. La primera guerra mundial llevó a una caída de la producción, a la implementación del patrón oro y a una crisis de representatividad en lo político. Predominan durante estos primeros años los pensamientos de izquierda. El Ecuador veía eclosionar durante la década de los veinte procesos que se desarrollaban desde el siglo XIX. Casi finalizado dicho siglo, imperaba el poder a mano de los liberales y ya en 1895 , la Revolución Liberal habría triunfado y se desenvolvería casi sin interrupción hasta la muerte de Eloy Alfaro en 1912. Esta Revolución Liberal se constituyó a partir de una serie de cambios de corte secular, cuyo propósito fue construir un Estado de ideología laica. El liberalismo del presidente Eloy Alfaro se enfocó en la separación de las esferas religiosa y civil en el Ecuador. Alfaro impondría una serie de medidas que dieron cabida a la interrupción del predominio de la Iglesia en competencias del Estado. El gobierno liberal propició 
Entre renglones rosas y azules, dos perspectivas de la mujer moderna. Una aproximación a las representaciones femeninas de 1919, en las revistas quiteñas Flora y Caricatura.1919, en las revistas quiteñas Flora y

el matrimonio, el divorcio civil, y la libertad de cultos ${ }^{1}$. Así mismo, fue importante el fomento de la educación laica y se favoreció la instrucción femenina mediante la creación de normales ${ }^{2}$.

Posterior a Alfaro, su sucesor Leónidas Plaza continuaría el legado también denominado liberalismo moderado desde 1912 hasta $1916^{3}$. Siguiendo a Plaza, los gobiernos de Alfredo Baquerizo Moreno (1916-1920), José Luis Tamayo (1920-1924) y Gonzalo Córdova (1924-1925) controlarían el país con un claro favoritismo a la banca privada y a los empresarios ${ }^{4}$.

Las primeras décadas del siglo XX heredaron los problemas decimonónicos. Así como en Francia e Inglaterra, las enfermedades persistían desde el siglo XIX ${ }^{5}$. La urbe quiteña experimentaba cambios acordes al discurso higienista como parte de las ideas modernistas. El 13 de julio de 1925 se crean ministerios y se proclaman medidas propuestas por el doctor riobambeño Ricardo Paredes para precautelar la salud y evitar la propagación de enfermedades contagiosas, tales como la peste blanca y la sífilis ${ }^{6}$. La pulcritud y el bienestar físico contribuían al estatus en la sociedad y a la construcción del ciudadano moderno.

Así mismo, luz eléctrica y agua potable llegaron a la ciudad en los primeros años de la década de los veinte. De la misma manera, para 1923 en Quito transitaban tranvías eléctricos, la población creció y con ella la ciudad. Además, empezaron a circular automóviles de gasolina, lo que forzosamente empujó la construcción de carreteras nuevas y más amplias, la transformación de casas y la construcción de parqueaderos. Los antiguos edificios, siguiendo los ritmos de la modernidad, eran restaurados o reemplazados con el arribo de materiales como el cemento, el hierro y el vidrio. El centro de la ciudad mostraba al mundo una fachada de nuevos edificios como el del diario El Comercio $^{7}$ (Grijalva, 2006). Los nuevos trazados de calles y

1 Tatiana Salazar Cortéz. La Delicada Resistencia: Representaciones de mujeres en tres revistas quiteñas. La Mujer, Flora y Alas. (Tesis de Licenciatura). Pontificia Universidad Católica del Ecuador, Quito. 2014.

2 Ana María Goetschel. Mujeres y educación en el periodo liberal. En El ferrocarril de Alfaro. El sueño de la integración, En: Sonia Fernández, comp. Quito, Ecuador: Corporación Editorial Nacional. (2009), 87 -100 .

3 Juan Paz y Miño. La Revolución Juliana en Ecuador (1925-1931) Políticas Económicas. Quito: Ministerio Coordinador de Política Económica (Historia de la Política Económica del Ecuador). 2013.

4 Juan Paz y Miño. La Revolución Juliana en Ecuador (1925-1931) Políticas Económicas. Quito: Ministerio Coordinador de Política Económica (Historia de la Política Económica del Ecuador). 2013.

5 Germán Rodas Chávez. El Pensamiento Higienista Público en el Periodo Liberal-Alfarista y Juliano y el Pensamiento de Salud Pública en el Periodo Juliano-Ayorista (Informe de Investigación). Universidad Andina Simón Bolívar, Quito. 2013.

6 German, Rodas Chávez. El médico Ricardo Paredes en el contexto del periodo de la década de los años 20 del siglo XX (Informe de Investigación). Universidad Andina Simón Bolívar, Quito. Disponible en: http://hdl.handle.net/10644/3814. (2010).

7 Wilson, Grijalva. Ferrocarril y modernización en Quito. Un cambio dramático entre 1905 y 1922. En Serie Magister, Universidad Andina Simón Bolívar. (2018). 
avenidas, la expansión de la ciudad, la urbanización de la misma y la presencia de automóviles eran puntos clave para tejer el entramado social y los determinantes del estatus.

Los espacios de lo cotidiano como el cine, el teatro y la ópera eran los focos de atención de quiteños y quiteñas. Por primera vez una película de Chaplin se proyectaba en el año de $1920^{8}$. En la Capital se exhibían películas de la Metro Goldwyn Mayer, de la Fox Pathé de New York y de la Warner Bross ${ }^{9}$. De la misma forma, se estrenaron comedias y óperas en las que las mujeres, como sujetos modernos, aparecían no solo como espectadoras, sino como protagonistas de dramas o reinterpretaciones literarias del siglo pasado. Además de cine, ópera y teatro, se inauguraron salones de patinaje como el Puerta del Sol al que asistían las jóvenes mujeres de la ciudad ${ }^{10}$. En fin, se quería reavivar la vida de la ciudad y la de los citadinos, dejar atrás lo viejo y permitir el paso de lo nuevo. Como hechos también sugerentes de la modernización cultural, podemos mencionar la creación de espacios como el café cantante, el Dinner concert ${ }^{11} \mathrm{y}$ sobre todo, la aparición de revistas ilustradas.

Con respecto a este último punto, son numerosas las publicaciones que surgen: Calenturas, Pomona, Bagatelas, Caritas y Carotas, Evolución, Savia, Hélice ${ }^{12}$, Caricatura y Flora. Estos espacios fortalecidos por la Revolución liberal cobran especial relevancia durante la década del veinte. Dentro de ellos se expresaron los ideales y una nueva estética moderna que destacaba las representaciones caricaturescas como expresiones modernas. Además, las ilustraciones cumplirían funciones publicitarias para productos de todo tipo ${ }^{13}$. A su vez, como parte de las actividades culturales enfatizadas durante la década del veinte, la poesía obtuvo un notable reconocimiento, se leía en periódicos, revistas y publicidad de todo tipo como un portavoz de las nuevas ideas. El modernismo literario se apoderaba del género poético en el Ecuador. El grupo de los decapitados habrían sentado ya las bases para dicho movimiento, influenciado en el Ecuador por Baudelaire y Rubén Darío. Las noches de bohemia de Medardo Ángel Silva, Arturo Borja, Humberto Fierro, Ernesto Noboa Caamaño, Jorge Carrera

8 Milton, Luna. Economía y Sociedad en el Ecuador de los años 20. En C. Marchán Romero (Ed), Crisis y cambios de la economía ecuatoriana en los años veinte, Quito: Banco Central del Ecuador, 17-45. (2013).

9 Wilma, Granda. La cinematografia de Augusto San Miguel: lo popular y lo masivo en los primeros argumentales del cine ecuatoriano. Guayaquil 1924-1925 (Tesis de maestría). Universidad Andina Simón Bolívar, Quito. Disponible en: http://hdl.handle.net/10644/906. (2006).

10 Ana María, Goetschel. Mujeres e imaginarios: Quito en los inicios de la modernidad. Quito: Abya Yala. Quito. (1999).

11 Caricatura, semanario humorístico de la vida nacional. Año 1, (1). (J0648). Biblioteca del Ministerio de Cultura y Patrimonio del Ecuador, Quito. (Diciembre de 1918)

12 María Helena, Bedoya. Los espacios perturbadores del humor. Banco Central del Ecuador. Quito. (2007).

13 Marilú, Vaca. Chicas chic: representación del cuerpo femenino en las revistas modernistas ecuatorianas (1917-1930). Procesos: Revista Ecuatoriana de Historia, 38(II). (2013). 
Entre renglones rosas y azules, dos perspectivas de la mujer moderna. Una aproximación a las representaciones femeninas de 1919, en las revistas quiteñas Flora y Caricatura.1919, en las revistas quiteñas Flora y

Andrade darían como resultado líneas que exaltaban la belleza, la sensualidad e idealizaban la figura femenina ${ }^{14}$.

En lo referente a la economía, los años, posteriores a la Primera Guerra mundial el país y sobre todo la costa ecuatoriana experimentan una fuerte crisis. La demanda de cacao disminuye notablemente y las importaciones se inclinan a la producción de caña de azúcar. Paralelamente, la economía serrana se dispara favorecedoramente, debido a la baja oferta de mercancías extranjeras, la sierra compensa el vacío con alimentos y textiles promoviendo una incipiente industrialización.

Dinamizando la producción nacional, la llegada del ferrocarril es fundamental. Durante la década toneladas de mercancías se empiezan a trasportar entre costa y sierra. Es evidente el fluido intercambio entre regiones. Para el año de 1922 se transportan 17.154 toneladas en mercancía. Consecuentemente, el auge económico llevó a que en la Sierra se diera paso a una modernización efervescente de antiguas haciendas y se promoviera la creación de nuevas fábricas textiles ${ }^{15}$. Al parecer, mientras más recursos adquiría la capital, más los gastaba, pues el volumen de importaciones crecía considerablemente. Los bienes foráneos arribaban al país cuantiosamente y sin dificultad $^{16}$. Es posible que la demanda de bienes extranjeros correspondiera a un factor de tipo social. Puesto que para la época, se imponía sobre todo el modelo parisino en la capital.

Los cambios bruscos en lo que se refiere a economía afectaron a diversos sectores de la población, sobre todo en la Costa, pero el momento permitió que otros surgieran y se consolidaran como la élite económica y por lo tanto social. La situación económica especialmente buena en la sierra, favorecida por la diversificación de la industria de cerveza, telas y cigarrillos, dio lugar no sólo a la bonanza financiera, notoria en infraestructura vial entre otras obras públicas, sino a una nueva configuración social que se gestaba desde finales del siglo XIX. Así pues, como banqueros y nuevos exportadores se posicionaban como autoridades sociales y emergían como nuevos ricos, una incipiente clase media se empezaba a configurar.

Se trata en líneas generales de procesos complejos que para el periodo a trabajar constituyeron hitos importantes para la recomposición de una sociedad que intentaba transitar del siglo XIX al XX. Pues, de los grandes acontecimientos mencionados superficialmente en líneas más arriba, brotaron como ramas manifestaciones políticas, económicas y culturales. Se hicieron presentes desde políticas higienistas, mejoramientos de la infraestructura urbana, atención a actividades culturales de diversa

14 Gloria, Valencia. El círculo modernista ecuatoriano: crítica y poesía. Quito:Abya-Yala, (2007).

15 Milton, Luna. Economía y Sociedad en el Ecuador de los años 20. En C. Marchán Romero (Ed), Crisis y cambios de la economía ecuatoriana en los años veinte, Quito: Banco Central del Ecuador, 17-45. (2013).

16 Carlos, Marchán Romero. Crisis Nacional, Aprovechamiento Regional y Discriminación Social de sus Efectos Económicos (1920-1927). En C. Marchán Romero (Ed), Crisis y cambios de la economía ecuatoriana en los años veinte (pp. 263-309). Quito: Banco Central del Ecuador, (2013). 
índole, exaltación a la cultura extranjera, sobre todo la francesa, hasta la creación de lugares para la cultura del esparcimiento y la diversión pública.

Estas entre otras cosas formaron parte del discurso de modernidad imperante en el Quito que en su cotidianidad incluía estos elementos para autoconstruirse y renovarse. "La modernidad se constituyó en un proceso histórico-social que marcó un punto de giro en todos los órdenes de la vida humana" ${ }^{17}$. Así, la modernidad es:

[...] un fenómeno histórico, político, social y económico, cuya impronta afectó de una u otra manera a casi todo el mundo, tomando diferentes matices en dependencia del contexto, pero repitiendo algunas ideas claves que se objetivaban en un progreso de tipo urbano, industrial y sociocultural, definido muchas veces como modernización ${ }^{18}$.

La modernidad constituye un conjunto de cambios que reconfiguraron la sociedad quiteña. Los procesos históricos ya mencionados fueron los medios de circulación de las fuentes a investigar. Mencionar el auge de las revistas ilustradas y su fortalecimiento con la Revolución Liberal, por ejemplo, así como la aparición de nuevas corrientes literarias, son claves en el aparecimiento de las publicaciones Caricatura y Flora.

\section{Una mirada a las imágenes decimonónicas y de inicios del XX de mu- jer en Quito.}

Creemos erróneo encasillar las imágenes de la mujer de 1919 como enteramente producto del siglo XIX o completamente fruto de las ideas modernas. Sin embargo, hemos considerado que para identificar lo dicho o bien, para determinar si la división categórica de imágenes femeninas en 1919 era tajante, presentaremos brevemente ciertos rasgos que construían la imagen decimonónica.

Para propósitos de este trabajo, cuando hablemos de imágenes decimonónicas nos referiremos a dos puntos. En primer lugar, al visual. Para ello, intentaremos dar una idea general de la construcción estética de la imagen de mujer. Decimos general, pues reconocemos que, para tener una visión completa de la estética del siglo XIX e inicios del XX, se requiere del análisis de un repertorio visual amplio. Sin embargo, creemos que los retratos que presentaremos pueden dar una idea de la manera en la que se representaba a las mujeres en el mencionado espacio temporal.

Así, vemos el retrato en busto de una mujer de 1858 dentro de un tondo (Ver

17 Orlando Rafael, Laso Pastó. La imagen fotográfica de Guillermo Illesca en el contexto de la primera modernidad quiteña (1900-1930) (Tesis de maestría, 2016), FLACSO, Quito. Recuperado de: http://hdl.handle. net/10469/9407. (2016).

18 Orlando Rafael, Laso Pastó. La imagen fotográfica de Guillermo Illesca en el contexto de la primera modernidad quiteña (1900-1930) (Tesis de maestría, 2016), 8 FLACSO, Quito. Recuperado de: http://hdl. handle.net/10469/9407. (2016). 
Entre renglones rosas y azules, dos perspectivas de la mujer moderna. Una aproximación a las representaciones femeninas de 1919, en las revistas quiteñas Flora y Caricatura.1919, en las revistas quiteñas Flora y

figura 1). La retratada se presenta con el torso ligeramente ladeado, porta un vestido con detalles de encaje en el pecho y un chal sobre sus hombros. La Señora Quirico luce en el cuello un collar doble de perlas con un accesorio central vistoso, lleva aretes y un adorno floral en su cabello recogido. El rostro, que recibe sombra por el lado izquierdo, muestra una apariencia sana y su piel parece aporcelanada. Sobre sus mejillas el pintor ha colocado un rosa sutil a manera de rubor. El fondo no consta de ningún adorno adicional.

En segundo lugar, encontramos otro retrato de aproximadamente 1910 del fotógrafo Benjamín Rivadeneira (Ver figura 2). En esta segunda imagen se observa una joven ubicada dentro de un tondo, se presenta con el mismo formato de retrato en busto. El fotógrafo muestra a una mujer que porta sobre sus hombros un chal, una joya dorada en su cuello y luce un peinado recogido. Podemos notar en este retrato en particular la similitud con la pintura de Hagen. La fotografía aquí adjunta guarda ciertas características pictóricas. Así, es evidente el detalle en los pliegues del chal que parecen ser pintados con un pincel, el trabajo de luz y oscuridad se maneja con maestría. El rostro posee sombras sutiles y sus mejillas un rubor casi imperceptible.

La representación del sujeto femenino se ve reforzada por los rasgos ya citados en los retrados precedentes, tales como peinado, ropaje, adornos florales y joyas. Resaltamos, en los casos citados, la tersura y la textura aporcelanada de la piel. A propósito de ello y basándonos en un tratado de fisonomía de Ambrosío Bondía de 1650, podemos conjeturar que el pintor de este retrato, además de representar un fenotipo determinado, procuró otorgar la imagen de blancura, ya que sería un determinante de feminidad. Asi mismo, la presencia de carmesí en el rostro sería sinónimo de hermosura más no de inteligencia ${ }^{19}$.

Así pues, apreciamos una construcción estética que contempla composiciones cuidadas. La atención en las joyas, el peinado, la delicada pose y el tono pálido en la piel modelaban personajes rebosantes de feminidad y dignos representantes del bello sexo. En cuanto al retrato femenino, se advierte que la estética que lo construye tanto en fotografía como en pintura es similar. La postura ladeada, el peinado, el color sobre las mejillas, la apariencia de porcelana de la piel, la presencia de joyas vistosas, el contraste de luces y sombras y las características pictóricas presentes en el chal son recurrentes. De tal forma, observamos que ciertas fotografías femeninas aún para 1910 conservan la fórmula estilística de los retratos del siglo XIX

Por otro lado, al referirnos a imágenes femeninas del XIX hablamos de una idea de mujer. Durante el siglo XIX e inicios del XX, antes de la llegada de las prácticas discursivas modernas, se proyectaban diferentes imágenes femeninas. Cabe resaltar entre ellas dos protagonistas, ideadas por los discursos tanto garcianos como liberales.

19 José Enrique Laplana Gil. Un tratado de fisiognomía de 1650, Universidad de Zaragoza, 141-153. Disponible en: https://www.raco.cat/index.php/Scriptura/article/viewFile/94738/142656. (1996). 
Estos edificaron ideales femeninos, aparentemente distintos, pero que se sostenían profundamente en una misma base ${ }^{20}$. Por un lado, el garcianismo ${ }^{21}$, de la mano del presidente conservador Gabriel García Moreno, proponía la concepción de una mujer que cultivara sus virtudes, que ejerciese la moralidad religiosa, que practicase el dibujo o el bordado, dedicada al hogar, gustosa practicante de la caridad y claro está, católica. Por otro, el liberalismo a cargo del presidente Eloy Alfaro mantenía la idea de la mujer ligada indiscutiblemente al hogar, pero dándole una apertura en el campo laboral ${ }^{22}$.

Paralelamente a esta doble visión, en el siglo XIX existía otra concepción un poco más romántica alimentada por la poesía. Se caracterizaba en este espacio temporal a la mujer como ese ser bello, virtuoso, grácil, frágil y casi místico. En síntesis, la concepción romántica de la mujer se basaba en una extrema idealización de la misma.

\section{Los renglones rosas y azules...}

Las revistas Flora y Caricatura son dos publicaciones que circularon en los albores de los años veinte. Ambas de mucho interés, pero muy diferentes entre sí. Iniciaremos con la primera. Flora: Revista mensual de Literatura, Artes y Variedades, contó únicamente con 14 números publicados hasta 1920 por la Imprenta Nacional. Las editoras y administradoras Rosaura Emelia Galarza y Celina María Galarza se encargaron de la publicación mensual de los números, sin embargo, entre 1918 y septiembre de 1920, la actividad de la revista cesó. La falta de apoyo de la Cámara del Senado y problemas presupuestarios forzaron la interrupción total de Flora $^{23}$.

La de 1917 fue su primera edición y en ella se describieron muy claramente los ideales de la revista. Lo que pretendían las mujeres que la conformaban era la liberación femenina, sin embargo una liberación limitada. Si bien es cierto manifiestan que la mujer ya no pertenece sólo al hogar o al claustro, expresan el deseo de que, basándose en la virtud y con el auxilio de las "santas creencias", adquieran nuevos conocimientos sin salir de "su propio y natural terreno". Se habla de una verdadera emancipación femenina que se logrará a través de la instrucción de la mujer con el fin

20 Alexandra Sevilla, "Las mujeres ecuatorianas entre la práctica y el discurso (1895-1929)" (Tesis de maestría, Universidad Andina Simón Bolívar, 2001), 1-145.

21 El garcianismo comprendió un período histórico de 1860 a 1865. Denominado así por García Moreno, Presidente de la República del Ecuador. El régimen estuvo marcado por una ideología política conservadora y eminentemente católica. El mandatario ecuatoriano impulsó la ciencia, la tecnología y la construcción del ferrocarril. Igualmente, durante el garcianismo se facilitó la llegada de numerosas órdenes religiosas.

22 Ana María Goetschel, "Educación e imágenes de mujer". En Antología. Género, ed. Gioconda Herrera (Quito: FLACSO - Sede Ecuador: Junta de Andalucía), 9.

23 Tatiana, Salazar Cortéz. La Delicada Resistencia: Representaciones de mujeres en tres revistas quiteñas. La Mujer, Flora y Alas. (Tesis de Licenciatura). Pontificia Universidad Católica del Ecuador, Quito. 2014. 
Entre renglones rosas y azules, dos perspectivas de la mujer moderna. Una aproximación a las representaciones femeninas de 1919, en las revistas quiteñas Flora y Caricatura.1919, en las revistas quiteñas Flora y

de mejorar como esposa, hija o madre. Se hacen además comentarios sobre la educación en el Ecuador, sugiriendo que se debe reforzar la enseñanza de las tareas domésticas como el planchado o el lavado. Sin embargo, tales actividades del hogar debían impartirse de acuerdo al estatus social; puesto que, las mujeres de Flora reconocían dos tipos de mujer: aquellas acomodadas económicamente y aquellas cuyo propósito de vida era el servicio a quienes llamarían "las hijas del pueblo". Para las primeras, la música el arte y la literatura serían fundamentales para el cultivo del espíritu, mientras que para las segundas, estos temas les serían infructuosos ${ }^{24}$.

Las páginas siguientes de la revista estaban llenas de poemas y alusiones a la poetisa guayaquileña Dolores Sucre. Se incluyeron datos biográficos, obra literaria y se exaltó su talento para escribir. Numerosos poemas de mujeres recordaban con cariño a Dolores y la inmortalizaban como un personaje de honra y virtud. La revista, en páginas posteriores, incluía otras noticias de interés, como matrimonios de miembros de lo que en la revista se denominaba la créme quiteña. Otros artículos premiaban el buen desempeño académico de las estudiantes distinguidas del Colegio La Inmaculada o el Colegio Sagrados Corazones, colocando acerca de ellas una breve descripción $\mathrm{y}$ una fotografía dentro de un tondo.

En cuanto a la edición de 1919 se aprecia una sección dedicada a mujeres que merecían estar en "El álbum de Flora". Dentro de este se incluían a algunas poetisas e intelectuales del "bello sexo". En el álbum se colocaba una fotografía de la mujer y una reseña pequeña de sus logros ${ }^{25}$. Otras mujeres eran mencionadas en el apartado, debido a su belleza, estatus y virtud.

La fotografía de Beatriz Escudero Moscoso, por ejemplo, ocupaba toda una página en el álbum de Flora (Ver figura 3). Ella, participante del concurso de los Juegos Florales ${ }^{26}$, se muestra en un retrato de busto, luce una especie de túnica de pliegues pesados y gruesos. Su cabello lo luce suelto y con ondas suaves que enmarcan su rostro. La sombra en la foto roza parte de la faz y se encuentra en todo el telón de fondo.

El autor, Françoise Soulages, plantea que en los retratos fotográficos existe un ser dual. Este nuevo individuo resultaría de la fusión entre un personaje actuado y una persona real, entre una pose natural y una teatral que convergen en una misma imagen ${ }^{27}$. En este sentido, las prendas de vestir son disfraces, la pose y ubicación de la retratada dentro de la imagen son elementos que contribuyen a la creación de un actor efímero que existe sólo en la fotografía.

Hemos resaltado el planteamiento de Soulages, pues hemos notado que la ima-

24 "Proemio", Flora, revista femenil ilustrada. (1917), Quito, 4.

25 Flora, revista femenil ilustrada. (1917), Quito.

26 Concurso literario que galardonaba a poetas ecuatorianos y que incluía fotografías de señoritas de la alta sociedad quiteña que sirvieron como las musas inspiradoras del concurso.

27 Soulages, F. Capitulo 2. Del objeto del retrato al objeto de la fotografía en general. "Eso fue actuado". Estética de la fotografia (pp.72-85). Buenos Aires, Argentina: La Marca. (2005). 
gen de Beatriz Escudero Moscoso guarda similitud con la representación de Perséfone, la diosa del reino de los muertos de Dante Gabriel Rossetti (1874) (Ver figura 4). Además del cabello rizado, suelto y largo, la túnica pesada y la piel blanca y tersa destacan la mirada tierna pero apesadumbrada que también mantiene Beatriz. Consideramos que la fotografía quiso emular a Perséfone, no sólo en apariencia sino en actitud. Suponemos que el fotógrafo pretendió cargar la imagen de Beatriz con el sufrimiento, pero así mismo, con la fuerza de la implacable reina del inframundo.

Vida social, curiosidades y una sección de chistes eran también parte de la revista Flora. De igual manera, se incluía "la mesa revuelta", lugar de la publicación donde se brindaban consejos de limpieza o de cuidado personal, tales como cremas caseras para las arrugas o fórmulas para limpiar el oro, así como algunas recetas de cocina y consejos de $\operatorname{moda}^{28}$.

Ahora bien, ¿Qué imagen de mujer se puede visualizar? Presumimos que para las mujeres de Flora las ideas modernas se hacían presentes. Sin embargo, la llegada de estas supuso para ellas una confluencia entre la mencionada representación decimonónica y la moderna. Lo visto en Flora evidencia los matices y los puntos medios, pues ni una ni otra imagen se impusieron con demasiada violencia. De alguna manera, la mujer se apropió de los discursos modernistas. En las páginas de la revista está latente la mezcla, pues por un lado, se impulsa la salida femenina de los campos tradicionales, pero por otro, la sigue arrastrando hacia atrás ${ }^{29}$, recordándole que su lugar natural está en el hogar. Algunas actividades seguían siendo sólo ejecutables por los hombres.

Hemos observado que la mujer en Flora poseía una imagen todavía hogareña, con un rol y unas tareas específicas, pero con un campo de acción un poco más grande. También, notamos que era una mujer virtuosa, que encarnaba las buenas costumbres y cuidaba de su higiene y vestimenta, de ahí, que fórmulas de limpieza y contra las arrugas se incluyeran en la publicación. Así mismo, características como la generosidad y la caridad eran fundamentales en la concepción de mujer advertida en Flora.

En la revista se muestra, como noticia la acción encomiable de mujeres inglesas que visitaban a los soldados heridos durante la Primera Guerra Mundial. También, como una acción caritativa, se hablaba con mucho entusiasmo de una iniciativa para entrenar al personal del hogar. Para la época el servicio doméstico se consideraba inadecuado y, como parte de la ayuda, se ofrecía mejorarlo. De igual forma, y dado que en 1917 los colegios que citamos en líneas anteriores brindaban educación con bases católicas, la moralidad era primordial. Las estudiantes que exaltaba Flora eran chicas con destacado desempeño académico, sin embargo, su devoción hacia Cristo las convertía en representantes dignas de la institución y por supuesto de su sexo.

Por último, para completar la fórmula de mujer Flora se agrega el elemento

$28 \quad$ Flora, revista femenil ilustrada. Quito. (1919)

29 Nos referimos con esto no a un retroceso, sino más bien al querer conservar una imagen femenina del siglo pasado. 
Entre renglones rosas y azules, dos perspectivas de la mujer moderna. Una aproximación a las representaciones femeninas de 1919, en las revistas quiteñas Flora y Caricatura.1919, en las revistas quiteñas Flora y

romántico. Este, contraponiéndose a la industrialización mecánica, plasma en las mujeres un ideal de belleza. De acuerdo a este, la mujer se presenta suave, delicada y etérea. Muy relacionado a la representación romántica se encuentra el hecho de que muchas poesías e imágenes hacían alusión a elementos de la naturaleza, por ejemplo, se relaciona al sujeto femenino con la sutileza de una flor. Por tal razón, los retratos fotográficos de muchas mujeres de Flora son frecuentemente adornados por composiciones florales.

En síntesis, los tres elementos que se describieron en líneas anteriores configuraban el ideal de mujer como ejemplar del "bello sexo", concebido e ideado desde mentes femeninas, asimilado y seguramente modificado por sus lectoras. Las mujeres de clase alta buscaban espacios propios y al no encontrarlos, los creaban. Flora, por tanto, constituye un espacio de mujeres para mujeres, dentro del cual, ideas e ideales son reproducidos en un espacio "moderno" de participación femenina, que asimilaron ideas nuevas convirtiéndolas en propias.

La concepción de mujer en el caso de Caricatura es un poco diferente. Pero antes de iniciar, sintetizaremos lo contenido en la revista. Caricatura salió a la luz por primera vez a inicios del siglo XX, en el año 1918, sólo un año después de que saliera Flora. Caricatura era un semanario humorístico, lo que suponía que su contenido sería satírico y caricaturesco. Tal y como en el caso de Flora, por ser primera edición, los ideales de la publicación se expresaron con fuerza. Sobre todo se buscaba dar enorme importancia a la cultura, pues para los editores de Caricatura la del Ecuador era deficiente. Al mismo tiempo, los redactores calificaron al pasado de la nación de anticuado y autodenominaron la publicación como el ente que lograría realizar cambios en la sociedad quiteña a nivel cultural. Además, se pretendía mostrar la realidad del contexto local a través de la caricatura.

El contenido de la revista sería dictado por sujetos que eran parte de la élite quiteña. Suponemos lo dicho, dado que se sabe que la familia de Beatriz Escudero Moscoso, quien apareció en Flora, estaba involucrada en la política. Conocemos que su padre el Dr. Manuel Eduardo Escudero Viteri fue abogado, doctor, ministro de hacienda, presidente de la Cámara de Diputados, diputado y profesor, entre otros oficios. Escudero tuvo siete hijos, entre ellos a Gonzalo Escudero Moscoso, poeta y diplomático que incluso llegó a colaborar desde diciembre de 1918 en el semanario humorístico quiteño Caricatura ${ }^{30}$.

La publicación se inaugura con una entrevista al artista Camilo Egas. Se habla de su vida, formación artística, reconocimiento como pintor, influencias pictóricas, compradores de sus obras y su experiencia como profesor de litografía. Posteriormente, dentro de la revista, encontramos numerosa publicidad apoyando la literatura y la

30 Rodolfo, Pérez Pimentel. Diccionario Biográfico Ecuador. Disponible en: http://www. diccionariobiograficoecuador.com/contactame.php. (S.f). 
caridad. En Flora la literatura es alabada y exaltada, así como las mujeres que la practican. Por el contrario, en Caricatura, si bien se apoya la literatura, no se lo hace tanto como al arte, al que consideraban en el semanario como símbolo de lo moderno ${ }^{31}$.

Vemos, a su vez, anuncios publicitarios de nuevos automóviles con mujeres conduciéndolos (Ver figura 5) e historias de hombres en la ciudad que remarcaban las distinciones entre clases sociales. Muchos personajes eran ridiculizados, por ejemplo, en la revista se burlaban de quien no daba dinero para la caridad o bien de los hombres que pretendían ser ricos y mantenían una apariencia opulenta. Así como en Flora, también en Caricatura existía un álbum de mujeres. En Caricatura se denominaría "Álbum de bellezas femeninas", sección en donde se exhibía una serie de caricaturas de mujeres alargadas, distinguidas y a la moda. La caricatura en este caso no se utilizaba para burlarse, por el contrario, se hacía uso de ella para remarcar y enfatizar como bien lo dicen los editores de la revista.

Dentro de este primer numeral no se hace ninguna mención al hogar ni a la familia, aunque sí se refieren a la mujer como perteneciente del "bello sexo". Observamos dentro de la primera edición del semanario humorístico la confluencia de numerosos personajes de la esfera intelectual de la época. De tal forma, advertimos la presencia de actores de la literatura, el arte, la música o el teatro. Pintores como Camilo Egas, Víctor Mideros, o poetas y escritores como Humberto Fierro, Medardo Ángel Silva o Benjamín Carrión colaboraban con la publicación. Estos ofrecían ilustraciones, cuentos, poemas o bien otorgaban entrevistas que llenarían las páginas de la revista todas las semanas. Creemos que el semanario estaría dirigido a la clase alta de la ciudad de Quito o bien, a la emergente clase media de la capital, puesto que el contenido de Caricatura exaltaba un estilo de vida que incluía tardes en salones de patinaje, la concurrencia a conciertos, musicales y obras de teatro.

El aparecimiento de las revistas ilustradas Flora y Caricatura resalta también de un importante suceso en la historia ecuatoriana: por primera vez en el Ecuador se observa el nacimiento de una cultura del ocio.

Al parecer, las ideas modernas, que veían su referente en el país francés, se asimilaron con más coherencia en Caricatura, pues aquí la mujer parece autónoma, representada en ocasiones fumando, con atuendos elegantes, tacones altos y a veces con pieles sobre su cuello, muy parisinas (Ver figura 6). Así mismo, la ilusión de una modernidad asimilada estaba totalmente asentada. Dentro de la primera Caricatura no se habla demasiado poéticamente de la mujer, se la idealiza de diferente manera. Entonces, se la presenta como un potencial comprador, culta, distinguida, que disfruta de las nuevas actividades que le ofrece la ciudad. Como señala Ana María Goetschel, la apertura de un salón de patinaje en 1919 y el impulso al cine contribuyeron a crear esta nueva ima- 
Entre renglones rosas y azules, dos perspectivas de la mujer moderna. Una aproximación a las representaciones femeninas de 1919, en las revistas quiteñas Flora y Caricatura.1919, en las revistas quiteñas Flora y

gen de mujer moderna ${ }^{32}$. Dado que ahora, ya no sólo se tenía la opción de estar en casa, sino que era posible salir a disfrutar de una película u obra de teatro por simple placer.

No podemos dejar de mencionar que dentro de la edición de Carnaval de 1919 se publicaron numerosos artículos relacionados a la festividad. Notamos que en ellos se exaltó con insistencia la figura femenina. Se observa, por ejemplo, poemas alusivos a la belleza de mujeres, mas, se referían a una belleza clásica, se hablaba de una perfección griega, de un aire casi místico, de mujeres sensuales y ligeras, capaces de inspirar a los poetas, en fin, se hablaba de musas. Las líneas de los poetas resaltaban la cercanía de las mujeres con lo bello y etéreo de la misma naturaleza.

En cuanto a representaciones visuales, las revistas ofrecen muchas, de las cuales se ha elegido dos para compararlas. La primera de Flora, "La Reina de la Moda", que muestra a tres mujeres posando elegantemente (Ver figura 7). Sin embargo, su vestimenta dice mucho, esta imagen evidencia la ambigüedad en la representación femenina a principios de siglo. Tal parece ser una mezcla entre un vestido, propio del XIX, y uno más moderno de la década del veinte. Los sombreros también exponen la transición, uno de ala ancha y otro con pluma, ambos de los años veinte. No llega a ser un atuendo completamente moderno, pero se acerca muchísimo. Por otra parte, los cuerpos son alargados, pero aún no tienen la sensualidad de las mujeres de Caricatura. Esto se ha tomado en cuenta para ejemplificar mejor los matices de la imagen femenina y el proceso de cambio y transición de la misma. La portada de Flora, por otro lado, es una representación griega del cuerpo, pero en general, toda la composición recuerda a una obra del art nouveau (Ver figura 8).

De Caricatura se ha tomado una de las representaciones caricaturescas de la edición de 1919 (Ver figura 9). En ella es evidente que una concepción más moderna de mujer se ha aplicado para la representación visual, se observa un cuerpo alargado, sensual, las medias que usa la modelo resultan ser muy a la moda parisina. Sobre todo hemos querido resaltar que la ilustración muestra un cuerpo desnudo, además, deja ver a una mujer cuyo pudor es casi inexistente.

En Caricatura también se pueden apreciar otro tipo de representaciones de mujeres con labios rojos, peinados a la moda y finas facciones. (Ver figura 10)

\section{Consideraciones finales}

Con lo expuesto, hemos llegado a las siguientes consideraciones finales. En primer lugar, podemos conjeturar que no existió una única imagen de mujer para el año de 1919. Además de ello, hemos de tomar en cuenta que en Flora las mujeres fueron capaces de crear una revista para mujeres, esto sugiere que su voz, tal vez no tan es-

32 Ana María Goetschel, Mujeres e imaginarios: Quito en los inicios de la modernidad (Quito: AbyaYala, 1999), 36.

Artificios. Revista colombiana de estudiantes de historia. No. 15. Enero de 2020. ISSN. 2422-118X 
cuchada, existía. Los de la publicación eran por tanto sujetos, que ante los cambios, veían formas de acomodarse a ellos.

Mencionaremos a su vez que se aprecia un vago interés político. Las mujeres de Flora sugieren reformas educativas, lo que nos indica que se interesaban en lo que respectaba a su formación. En Flora se observaron tres puntos clave: la idea de mujer ligada al ámbito del hogar, la práctica y cultivo de la virtud y por último, una imagen femenina romántica. Conjeturamos que estos tres aspectos fueron los que contribuyeron a la construcción de una idea generada por mujeres y para mujeres.

También conjeturamos que, en lo que respecta a la educación de mujer, lo que se expresa en el "Proemio" de Flora recalca la diferencia entre aquello que deben aprender las mujeres de acomodada posición y aquello que deben saber las féminas hijas de obreros o artesanos. Por el contrario, en la revista Caricatura no se encuentra tal notoria distinción y al parecer, la mujer es únicamente bella, mística, sensual y moderna.

Por otra parte, determinamos que la imagen que se concibió en el proyecto editorial de Caricatura fue la de una mujer que se presentaba elegante, fumaba y se relacionaba con artistas, poetas y literatos, casi como una parisina. Para los editores de la revista, la mujer ya no era sólo aquel ser grácil, etéreo o romántico, ahora ella era distinguida e incluso sensual. Sin embargo, hemos de decir que dichas ideas sobre el sujeto femenino que se han visto en las ediciones de 1919 no fueron del todo diferentes entre sí. Así por ejemplo, en ambas publicaciones emplean el término de "bello sexo" para referirse al género femenino. Del mismo modo, reconocen las influencias de la modernidad en Europa y la necesidad de asimilarla; en los dos casos las revistas son claros exponentes de una emergente cultura del ocio, que junto con el teatro, el cine o el patinaje, se desarrollaron rápidamente durante la década de los veinte en Quito.

También hemos determinado que, ya en los albores de la década del veinte, las imágenes del siglo XIX pervivían. Así por ejemplo, en Flora se observa que la mujer aún buscaba ser piadosa, caritativa, religiosa y devota de su hogar, a pesar de haber reconocido la presencia de "lo moderno". En fin, se observa, tanto en Caricatura como en Flora, una conjunción de ideas que conservaba la idea de mujer decimonónica como un pilar fundamental.

En cuanto a la parte visual de las publicaciones podemos conjeturar que las representaciones femeninas evidenciaron el cambio. Pudimos apreciar que las ilustraciones de Caricatura, así como los artículos de la revista, observaron una influencia más fuerte de la vanguardia europea, los rasgos estilizados, las proporciones exageradas, los trazos bidimensionales y los colores sólidos. No así las fotografías e ilustraciones de Flora, que guardaron una composición más clásica, reflejando al mismo tiempo el recato propio de la revista. Sin embargo, cabe resaltar que así como en Flora, en Caricatura también se advierten elementos clásicos, sobre todo en la edición de Carnaval. La perfección griega y los rasgos escultóricos eran exaltados, así pues, las mujeres fueron catalogadas de bellezas estatuarias y perfectas. 
Entre renglones rosas y azules, dos perspectivas de la mujer moderna. Una aproximación a las representaciones femeninas de 1919, en las revistas quiteñas Flora y Caricatura.1919, en las revistas quiteñas Flora y

\section{Fuentes consultadas}

“Anuncio publicitario". En Caricatura. (Figura 5). (1919).

Beatriz Escudero Moscoso. En Flora, revista femenil ilustrada. (Figura3). (1919).

Bedoya, María Helena. Los espacios perturbadores del humor. Banco Central del Ecuador. Quito. (2007).

Caricatura, semanario humorístico de la vida nacional. Año 1, (1). (J0648). Biblioteca del Ministerio de Cultura y Patrimonio del Ecuador, Quito (Diciembre de1918).

Caricatura, semanario humorístico de la vida nacional. Año 1, (12). (J0648). Biblioteca del Ministerio de Cultura y Patrimonio del Ecuador, Quito (2 de marzo de 1919).

"Carnestolendas" Caricatura, semanario humorístico de la vida nacional, 2 de marzo de, 1, 12. (1919).

"Editorial", Caricatura, semanario humorístico de la vida nacional, Diciembre de 1918, 1, 1. (J0648). Biblioteca del Ministerio de Cultura y Patrimonio del Ecuador, Quito.

“El comentario galante”. En Caricatura. (Figura 6). (1919).

Flora, revista femenil ilustrada. (BA10398), Biblioteca del Ministerio de Cultura y Patrimonio, Fondo de Ciencias Humanas, Quito. (1917).

Flora, revista femenil ilustrada. (BA10398), Biblioteca del Ministerio de Cultura y Patrimonio, Fondo de Ciencias Humanas, Quito. (1919).

Goetschel, Ana María. Mujeres e imaginarios: Quito en los inicios de la modernidad. Quito: Abya - Yala, 38 (1999).

Goetschel, Ana María. “Educación e imágenes de mujer”, en Antología. Género, editado por Gioconda Herrera, 9. Quito: FLACSO - Sede Ecuador: Junta de Andalucía. (2001). 
Goetschel, Ana María. "Musas, ondinas y misses: estereotipos de las mujeres quiteñas en los años treinta del siglo XX", en Íconos: Revista de Ciencias Sociales, 20 110-113. (2004). DOI: https://doi.org/10.17141/iconos.20.2004.63

Goetschel, Ana María. Mujeres y educación en el periodo liberal. En El ferrocarril de Alfaro. El sueño de la integración, En: Sonia Fernández, comp. 87 -100. Quito, Ecuador: Corporación Editorial Nacional. (2009).

Granda, Wilma. La cinematografia de Augusto San Miguel: lo popular y lo masivo en los primeros argumentales del cine ecuatoriano. Guayaquil 1924-1925 (Tesis de maestría). Universidad Andina Simón Bolívar, Quito. Disponible en: http:// hdl.handle.net/10644/906. (2006).

Grijalva, Wilson. Ferrocarril y modernización en Quito. Un cambio dramático entre 1905 y 1922. En Serie Magister, Universidad Andina Simón Bolívar. (2018).

Hagen, A. Señora Quirico. Pintura sobre tela. Casa de la Cultura Ecuatoriana. (Figura 1). (1858).

Laplana Gil, José Enrique. Un tratado de fisiognomía de 1650, Universidad de Zaragoza, 141-153. Disponible en: https://www.raco.cat/index.php/Scriptura/article/viewFile/94738/142656. (1996).

Laso Pastó, Orlando Rafael. La imagen fotográfica de Guillermo Illesca en el contexto de la primera modernidad quiteña (1900-1930) (Tesis de maestría, 2016), 8 FLACSO, Quito. Recuperado de: http://hdl.handle.net/10469/9407. (2016).

"La reina de la moda". (1919). En Flora. (Figura 7).

Luna, Milton. Economía y Sociedad en el Ecuador de los años 20. En C. Marchán Romero (Ed), Crisis y cambios de la economía ecuatoriana en los años veinte, Quito: Banco Central del Ecuador, 17-45. (2013).

Marchán Romero, Carlos. Crisis Nacional, Aprovechamiento Regional y Discriminación Social de sus Efectos Económicos (1920-1927). En C. Marchán Romero (Ed), Crisis y cambios de la economía ecuatoriana en los años veinte (pp. 263309). Quito: Banco Central del Ecuador, (2013).

Paz y Miño, Juan. La Revolución Juliana en Ecuador (1925-1931) Políticas Económicas. Quito: Ministerio Coordinador de Política Económica (Historia de la 
Entre renglones rosas y azules, dos perspectivas de la mujer moderna. Una aproximación a las representaciones femeninas de 1919, en las revistas quiteñas Flora y Caricatura.1919, en las revistas quiteñas Flora y

Política Económica del Ecuador). (2013).

Paz y Miño, Juan. La Revolución Juliana en Ecuador (1925-1931) Políticas Económicas. Quito: Ministerio Coordinador de Política Económica En Historia de la Política Económica del Ecuador. (2013).

Pérez Pimentel, Rodolfo. Diccionario Biográfico Ecuador. Disponible en: http://www. diccionariobiograficoecuador.com/contactame.php. (S.f).

“Portada”. En Flora. (Figura 8). (1917).

"Pudor de modelo". En Caricatura. (Figura 9). (1919).

"Proemio", Flora, revista femenil ilustrada. Quito, 4. (1917).

Retrato de mujer. En Caricatura. (Figura 10). (1919).

Rivadeneira, B. Sin título. Banco Central del Ecuador. (Figura 2). (ca. 1910).

Rodas Chávez, German. El médico Ricardo Paredes en el contexto del periodo de la década de los años 20 del siglo XX (Informe de Investigación). Universidad Andina Simón Bolívar, Quito. Disponible en: http://hdl.handle.net/10644/3814. (2010).

Rodas Chávez, German. El Pensamiento Higienista Público en el Periodo Liberal-Alfarista y Juliano y el Pensamiento de Salud Pública en el Periodo Juliano-Ayorista (Informe de Investigación). Universidad Andina Simón Bolívar, Quito. 2013.

Rossetti, D.G. Perséfone. Óleo sobre lienzo. En: Tate Britain, Londres. (Figura 4). (1874).

Salazar Cortéz, Tatiana. La Delicada Resistencia: Representaciones de mujeres en tres revistas quiteñas. La Mujer, Flora y Alas. (Tesis de Licenciatura). Pontificia Universidad Católica del Ecuador, Quito. 2014.

Sevilla, Alexandra. "Las mujeres ecuatorianas entre la práctica y el discurso (18951929)" Tesis de maestría, Universidad Andina Simón Bolívar. (2001). 
Soulages, F. Capitulo 2. Del objeto del retrato al objeto de la fotografia en general. "Eso fue actuado". Estética de la fotografia (pp.72-85). Buenos Aires, Argentina: La Marca. (2005).

Vaca, Marilú. "Chicas chic: representación del cuerpo femenino en las revistas modernistas ecuatorianas (1917-1930)" en Procesos, Revista ecuatoriana de Historia. 73-93. (2013).

Valencia, Gloria. El círculo modernista ecuatoriano: crítica y poesía. Quito:Abya-Yala, (2007). 